\title{
An avoidable complication of digital nerve block
}

\author{
J O’Donnell, K Wilson, P A Leonard
}

\section{Accident and Emergency Department, Royal Infirmary of Edinburgh, Lauriston Place, Edinburgh EH3 9YW, UK}

Correspondence to: Dr Leonard (paul_leonard@ cableinet.co.uk)
Digital nerve block is a commonly used regional anaesthetic technique, often performed in the accident and emergency (A\&E) department. It is a safe and effective technique that has been shown to have few complications. ${ }^{1}$ When lignocaine (lidocaine) is used, the digit will be anaesthetised for approximately 45 minutes to one hour, which is adequate anaesthetic time for most procedures undertaken in the A\&E department. ${ }^{2}$

A 66 year old man presented to the A\&E department with a $1.5 \mathrm{~cm}$ incised wound to the ulnar aspect of his right ring finger, sustained while using a Stanley knife at work. There was no evidence of digital nerve injury or tendon damage. A digital nerve block was performed and the wound was cleaned and explored. It was repaired using three sutures and the patient was discharged to the care of his general practitioner for removal of the sutures.

On the patient's arrival home, about $40 \mathrm{~min}$ utes after the administration of the ring block, he made a cup of tea. As he carried the cup he accidentally dipped the tip of his anaesthetised finger into the hot tea. He felt no pain at the time but later noticed that he had sustained a burn to the tip of his finger. He re-presented to the department one week later with a partial thickness, almost circumferential burn to the tip of his finger (fig 1) This required repeated dressings over a four week period at the plastic surgery dressings clinic before it had satisfactorily healed.

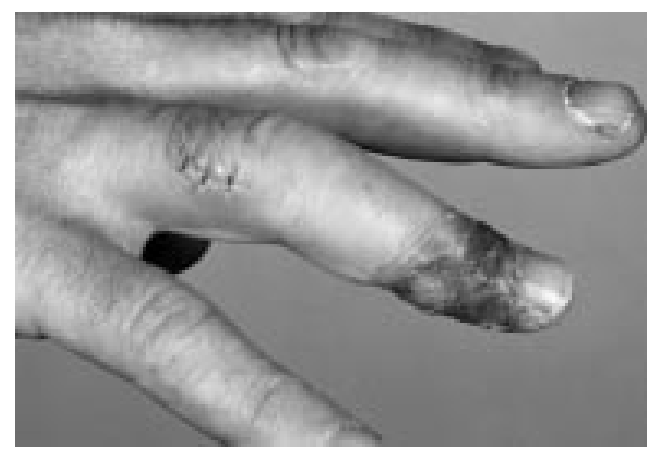

Figure 1 Photograph showing finger tip burn and healing laceration.

Sensation loss and thus loss of the protective reflexes of the finger can persist for up to one hour after a digital nerve block, making the finger susceptible to subsequent injury. This case illustrates the importance of warning the patient of this risk in order to prevent injuries such as the thermal injury seen in our case.

We would like to thank Dr P Freeland, consultant in Accident and Emergency Medicine, St John's Hospital, Livingston for his permission to report on this patient.

Conflicts of interest: none.

Funding: none.

1 Low CK, Wong HP, Low YP. Comparison between single injection transthecal and subcutaneous digital blocks. $\mathcal{F}$ Hand Surg [Br] 1997;22:582-4.

2 Illingworth KA, Simpson KH. Anaesthesia and analgesia in emergency medicine. Oxford: Oxford University Press, 1998: 335. 